\title{
Does nuclear energy produce neodymium? Negative perception of nuclear energy drives the assumption that it is polluting
}

\author{
Alicia Herrera-Masurel ${ }^{\dagger}$, Sacha Altay ${ }^{\dagger} \&$ Hugo Mercier ${ }^{*}$ \\ Institut Jean Nicod, Département d'études cognitives, Ecole normale supérieure, Université PSL, \\ EHESS, CNRS, 75005 Paris, France ${ }^{1}$
}

In press at: Journal of Experimental Psychology: Applied

\begin{abstract}
The public tends to exaggerate the dangers of nuclear energy, mistakenly associating it with various environmental problems such as ozone depletion and the production of CO2. First, we investigate the acquisition of misconceptions about nuclear energy. In Experiments 1 ( $N=198$, UK) and $2(\mathrm{~N}=204$, France) participants were more likely to develop new negative misconceptions about nuclear energy, compared to renewables or even some fossil fuels. Participants were also more likely to attribute the emission of hazardous substances produced by renewables to nuclear energy than to the energy sources actually emitting it. This suggests that specific misconceptions about nuclear energy are likely the byproducts of negative perceptions of nuclear energy. Second, we ask whether correcting specific misconceptions leads to less negative attitudes about nuclear energy. In Experiments $3(\mathrm{~N}=296, \mathrm{UK})$ and $4(\mathrm{~N}$ $=305$, France), participants were exposed to pro-nuclear energy arguments, one of which informed them of its low $\mathrm{CO} 2$ emissions. This argument led to a decrease in the perception that nuclear energy contributes to climate change. Thus, even if specific misconceptions about nuclear energy derive from overall negative perceptions, addressing these misconceptions can still help align public opinion with expert opinion.
\end{abstract}

\footnotetext{
$1 \uparrow$ denotes equal contribution, * denotes corresponding author.
} 


\section{Public Significance Statement}

We show that people are more likely to develop novel negative misconceptions about nuclear energy than about other energy sources. However, one of the most salient of these misconceptions--that nuclear energy emits large amounts of $\mathrm{CO} 2$ - can be corrected, which then mitigates the perception that nuclear energy contributes to climate change.

\section{Introduction}

On the topic of nuclear energy, there are systematic divergences between public and expert opinion, also known as consensus gaps (see, Cook \& Jacobs, 2014). Experts—but not the public-agree that nuclear energy has no negative health consequences during normal operation, and that rare incidents such as the Chernobyl disaster only caused a relatively low number of casualties (Boice et al., 2003; Sermage-Faure et al., 2012; UNSCEAR, 2017). The public also largely fails to grasp the potential of nuclear energy for mitigating climate change. For instance, people across the world believe that nuclear energy emits significant amounts of CO2 (IPSOS, 2020, BVA, 2019) despite the fact that the CO2 emission of nuclear energy are actually very low, and that this fact is not even contentious (Kharecha \& Hansen, 2013; Myhrvold \& Caldeira, 2012). Other studies have found that nuclear waste was mistakenly associated with the depletion of the ozone layer (Pekel, 2005). These misconceptions, in which nuclear energy is mistakenly perceived as damaging to the environment in specific ways, might be problematic, as they could lead people to overlook a potentially valuable tool in the fight against climate change (Allen et al. 2018).

The goal of this paper is twofold. First, we attempt to understand why people believe that nuclear energy emits pollutants it does not actually emit (or does not emit in significant amounts). More specifically, we measure the acquisition of misperceptions about nuclear 
energy, testing whether participants are more likely to develop new negative misperceptions of

nuclear energy than of renewable energy sources (e.g. that they emit a harmful made-up substance). We reasoned that this effect would be driven by negative prior beliefs about nuclear energy. Second, we study the consequences of the belief that nuclear energy emits $\mathrm{CO} 2$ in particular: can correcting this misbelief lead to a more positive perception of nuclear energy, and of its potential role in fighting climate change?

We now briefly review the literature on the consensus gaps regarding nuclear energy, before introducing the experiments.

\subsection{Consensus gaps on nuclear energy}

As mentioned above, experts agree that nuclear power has no negative health consequences during normal operation. The estimate for the deaths linked to the (rare) nuclear incidents are more disputed, but they are close to zero for all but one incident (Chernobyl) (Boice et al., 2003; Sermage-Faure et al., 2012; UNSCEAR, 2017). Besides the clear consensus on the fact that nuclear power emits very low levels of $\mathrm{CO} 2$ (comparable to those of renewable energies), there is a broad agreement that it should be part of the solution to fight climate change (Budnitz, 2016; Cameron \& Taylor, 2011; Nuclear Energy Institute, 2019; OECD, 2012).

Public opinion, however, diverges from this scientific consensus. This divergence bears both on general opinion and on specific beliefs. At a broad level, a 2005 poll conducted in 18 countries showed that the risks of nuclear power as an energy source were judged by a majority of respondents to outweigh its advantages, while only one third thought that the advantages outweigh the risks (GlobeScan, 2005). In 2014, nearly twice as many people in Europe opposed rather than supported the use of nuclear energy in their country (Eurobarometer, 2014). 
Moreover, and contrary to expert opinion, a positive attitude toward climate change mitigation is associated with a more negative attitude toward nuclear power (Vainio, 2017).

The consensus gap is even clearer on specific points. On the dangers of nuclear accidents, a recent study showed that participants in the UK overestimated the deaths due to radiation after the Fukushima Daiichi incident by a factor of 1000 (Hacquin et al. 2022; Rozin, 2001). Another study found that a majority of Turkish high school students believed radioactive waste from nuclear power to be an ozone depletion factor (Pekel, 2005). A 2019 international survey showed that, on average across 30 countries, $26 \%$ of participants believed that nuclear energy emitted a lot of $\mathrm{CO} 2,27 \%$ believed that it emitted a significant amount, while only $37 \%$ believed it emitted little or no $\mathrm{CO} 2$ at all (which can both be considered appropriate answers) (IPSOS, 2020). Even in the countries with the most accurate answers, nearly a third of participants overestimated the production of $\mathrm{CO} 2$ by nuclear energy. In France and in the UK, where the current experiments took place, respectively $50 \%$ and $40 \%$ of the participants considered that nuclear energy emits a significant amount of CO2 (see also, BVA, 2019).

What is the source of these consensus gaps? One possibility is that people develop specific misconceptions, and that these misconceptions lead to more general negative opinions towards nuclear energy. For instance, people could glean in different places the belief that nuclear energy emits large amounts of $\mathrm{CO} 2$, which would lead to a general dislike of this energy source, in particular of its role in fighting climate change. A second possibility is that people develop a generally negative view of nuclear energy (for a variety of reasons, a point we expand on in the conclusion), and that this broadly negative view, in the absence of existing specific beliefs to the contrary, leads them to assume the worst about nuclear energy. For example, people might not know how much $\mathrm{CO} 2$ nuclear energy emits but, because they have a broadly negative 
view of nuclear energy, and they know emitting $\mathrm{CO} 2$ is bad for the environment, they assume nuclear energy emits large quantities of $\mathrm{CO} 2$.

In favor of the first possibility — that specific misconceptions drive a general dislike of nuclear energy - is the presence, in some media, of these misconceptions. For example, in 2018 Greenpeace France published a ranking of energy sources according to their $\mathrm{CO} 2$ emission, in which nuclear energy was ranked as a significant emitter of $\mathrm{CO} 2$, above energy sources such as solar (when in fact it emits equal or less CO2 than solar energy, see ADEME 2022; NREL 2022). This ranking was widely covered by the French media (such as 20 minutes, Le Figaro, or Le Monde). However, such examples of specific misconceptions in mainstream media remain relatively rare.

In the first part of this article, we test the second hypothesis, that general negative perceptions of nuclear energy drive the acquisition of negative misconceptions about nuclear energy. A wide range of theoretical frameworks on the role of beliefs to justify pre-existing attitudes support this hypothesis. Previous work in cognitive science has shown that people engage in motivated reasoning, by generating reasons —including new beliefs - to justify pre-existing conclusions (Haidt, 2001; Kunda, 1990; Mercier \& Sperber, 2011). In the domain of political science, motivated reasoning is used to explain why political misperceptions tend to be largely politically congruent, in the sense that people acquire and hold misconceptions that fit with their broad political views (Flynn et al., 2017). Similarly, pre-existing political identities are theorized to drive the acquisition of specific belief that allow people to justify and reinforce their identities (Williams, 2022). One way to study the acquisition of new misconceptions is to use misconceptions that are unlikely to predate the experiment, or that we completely make up, and measure how willing participants with various pre-existing attitudes and beliefs are to 
believe such misconceptions. Similar studies have found that people's pre-existing attitudes drive the acquisition of congenial (made-up) misconceptions (Oliver \& Wood, 2014).

Our first goal here is twofold: (i) to test whether people are more likely to develop negative misconceptions about nuclear energy than other energy sources viewed more favorably by the public (e.g. renewables), and (ii) to test whether people are more likely to develop negative misconceptions about nuclear energy than neutral misconceptions (again compared to energy sources viewed more favorably).

Our second goal is to test whether correcting specific misconceptions about nuclear energy leads to more positive attitudes toward nuclear energy. Studies suggest that factual corrections tend to reduce misperceptions, with some belief updating in the expected direction (van der Linden et al., 2015, Guess \& Coppock, 2018; Wood \& Porter, 2019, for some debates on the degree of effectiveness of these corrections, see, Ecker and Ang, 2018; Kahan, \& Corbin, 2016; Nyhan and Reifler, 2010). The issue of whether correcting specific misconceptions has an effect on broader attitudes is much murkier. Some experiments have found that correcting misconceptions has little effect on people's underlying attitudes or behaviors (Barrera et al., 2020; Porter et al., 2022). In other studies, however, corrections of misconceptions have been found to affect broader attitudes (at least in the domain of health misinformation, see, Walter et al., 2021). On the topic of nuclear energy in particular, a study suggested that arguments from credible sources about the potential benefits of nuclear energy could be effective (Wang, 2020), and another showed that arguments explaining the limited dangers of nuclear radiation during normal functioning of nuclear power plants led to a more positive opinion of nuclear energy (Hacquin et al. 2022, although see Ho et al. 2018). 


\subsection{The present experiments}

In Experiments 1 and 2, we investigate the acquisition of misconceptions about nuclear energy. To do so, participants were asked the extent to which various forms of energy productionincluding nuclear energy - rely on various substances, most of which are pollutants. Crucially, nuclear enegy relies on only one of these substances (tritium), while the other substances are completely absent from nuclear energy production. An advanced Google search conducted in September 2022 with the terms "nuclear energy" and "neodymium" or "nitrogen trifluoride" confirmed that no news article in the first ten Google pages had claimed that nuclear energy relies on these substances, which is to be expected because these substances are not well-known from the public and because nuclear energy doesn't rely on them. It is thus unlikely that participants could have acquired the belief that nuclear energy emits such substances prior to the experiments. If, nonetheless, participants believed that nuclear energy emits these substances, it would suggest that they had developed the misconception on the spot, and that this misconception is thus derived from people's beliefs about nuclear energy (e.g. that it emits various kinds of harmful substances). To make stronger causal claims about the acquisition of these new negative misconceptions, we also asked participants about substances that we had made-up, in which case we can be certain that the participants did not hold any misconception prior to the experiment (a technique used in the literature on overclaiming, see, e.g., Paulhus \& Harms, 2003; Atir et al., 2015).

In Experiments 3 and 4 we give participants arguments containing evidence that nuclear power emits low amounts of $\mathrm{CO} 2$, and test whether these arguments make participants more favorably disposed towards the reliance on nuclear energy to fight climate change. Since studies have observed an effect of misconception correction on broader attitudes in scientific domains, and in the domain of nuclear energy in particular, it is plausible that the same effect would be 
observed here, and thus that correcting the misperceptions that nuclear energy emits large amount of $\mathrm{CO} 2$ might affect broader attitudes towards it (e.g. whether nuclear energy is responsible for climate change).

Experiments 1 and 3 were conducted with U.K. participants, and Experiments 2 and 4 with French participants. These countries were chosen partly because of convenience, but they also have desirable properties. First, although both countries rely to a very different extent on nuclear power (approximatively 15\% in the U.K and 70\% in France), they both have nuclear reactors, making public opinion on the topic in each country very relevant (see for instance the importance of public opinion for the closure of nuclear plants in Germany, Nam et al., 2021). Second, as mentioned above, the misperception that nuclear power emits substantial amounts of $\mathrm{CO} 2$ was widespread in both countries.

\section{Experiments}

\section{Transparency and Openness}

We pre-registered each of the experiments' sample size, exclusion criterion, hypotheses, research questions, and statistical analyses. Data, scripts, and pre-registrations are available at https://osf.io/4ujbw/ (Masurel et al. 2022). The reported analyses that were not pre-registered are in the 'exploratory analyses' sections.

In the statistical analyses below, we refer to 'statistically significant' as the p-value being lower than an alpha of 0.05 . The Confidence Intervals (CI) reported are $95 \%$. All statistical analyses were conducted in R (v.4.0.3), using R Studio (v.1.3.1093). The reported betas (B) come from ordinary least squares (OLS) regressions, while the correlation coefficients (r) are 
Pearson correlation coefficients. All statistical models are available in the pre-registration documents and in the R scripts accessible on OSF (https://osf.io/4ujbw/).

\section{Experiment 1}

The main goal of Experiment 1 is to test whether participants believe that nuclear energy relies on various harmful substances. Participants are asked whether five energy sources (several renewables, fossil fuels, and nuclear energy) rely on four substances. One substance was tritium, which is produced by nuclear power plants; the second was nitrogen trifluoride, a substance used to produce solar panels; the third was neodymium, a substance used to produce the motors of wind turbines; the fourth was drisonium, a made-up substance. All four substances were described as harmful (accurately for the three real substances). If participants believe that nuclear energy relies on nitrogen trifluoride or neodymium it is unlikely to be because of previously learned associations between nuclear energy and these substances — and impossible in the case of drisonium.

- H1: Participants estimate that nuclear energy relies on tritium more than the other energy sources, each considered separately.

- H2: Participants estimate that nuclear energy relies on nitrogen trifluoride more than solar energy.

- H3: Participants estimate that nuclear energy relies on neodymium more than wind turbines.

- H4: Participants estimate that nuclear energy relies on drisonium more than renewable energy, and natural gas, considered separately.

We also used Experiment 1 to establish a series of negative beliefs about nuclear energy. First, we wanted to confirm the existence of the misconception that nuclear energy emits significant amounts of $\mathrm{CO} 2$ 
- H5: Participants consider that nuclear power plants emit more CO2 than renewable energies (a), and natural gas (b), considered separately.

Secondly, we tested whether participant hold the belief that nuclear energy is harmful to the environment:

- H6: Participants consider that nuclear power plants are more harmful for the environment than renewable energies (a), and natural gas (b), considered separately.

Finally, we investigated the relationship between the specific misconception that nuclear energy emits $\mathrm{CO} 2$ and the belief that it is harmful to the environment:

- H7: Considering nuclear energy as harmful to the environment correlates with the belief that it emits $\mathrm{CO} 2$.

\section{Participants}

Based on a pre-registered power analysis, we recruited 200 U.K. participants on Prolific Academic. We removed two participants who failed the attention check, leaving 198 participants (140 women, $\left.M_{\text {Age }}=37.21, S D=12.56\right)$.

\section{Materials, Design and Procedure}

The present research received approval from an ethics committee (CER-Paris Descartes; $\mathrm{N}^{\circ}$ 2019-03-MERCIER). Participants had to complete a consent form and an attention check (see Electronic Supplementary Materials (ESM)). Then, participants were asked about the danger they thought nuclear, natural gas, coal, wind, solar, and hydroelectric energy sources represented for the environment, and the amount of $\mathrm{CO} 2$ they emitted, with the two following questions: "How harmful do you think each of the following energy sources is for the environment?”' ([Not at all], [Very little], [Little], [Somewhat], [Very], [Extremely]), and 
"How much CO2 do you think each of the following energy sources emits?" ([Not at all], [Very little], [Little], [Some], [A lot], [A great deal]).

Participants were then asked the extent to which these energy sources relied on four substances: tritium, nitrogen trifluoride, neodymium, and drisonium. "[Substance name] is a dangerous substance that some energy sources rely on to produce electricity. To what extent do you think each of the following energy sources relies on [Substance name]?" ([Not at all], [Very little, [Little], [Some], [A lot], [A great deal]). Finally, participants provided demographic information. Figure 1 offers an overview of the substances used in Experiment 1 and Experiment 2.

\section{Experiment 1}

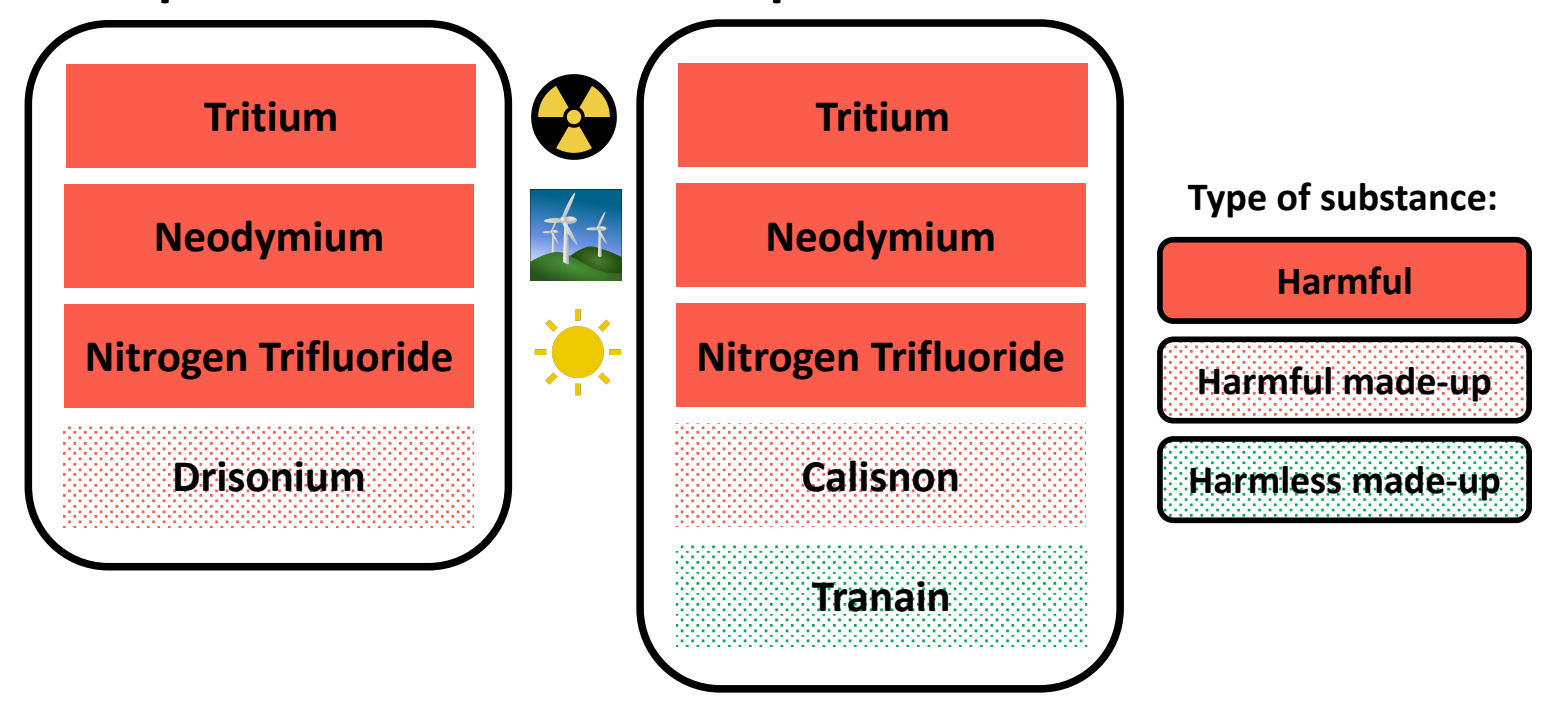

Figure 1. Overview of the substances used in Experiments 1 and 2. Tritium is emitted by nuclear energy, neodymium is used to produce wind turbines, and nitrogen trifluoride is used to produce solar panels. All three are harmful and were described as such. The other three substances are made-up.

\section{Results}


We conducted ordinary least squares (OLS) regressions and controlled for multiple comparisons by applying the Benjamini-Hochberg method to H1-7 (which controls for the False-Discovery Rate and has a less negative impact on statistical power than alternative methods).

In support of $\mathrm{H} 1$, participants estimated that nuclear energy relies on tritium more than renewables $(\beta=1.25, \mathrm{t}(790)=18.16, \mathrm{p}<.001)$, natural gas plants $(\beta=0.99, \mathrm{t}(394)=11.33, \mathrm{p}$ $<.001)$, and coal $(\beta=0.90, \mathrm{t}(394)=10.02, \mathrm{p}<.001)$. Although this pattern fits with the accurate answer, since only nuclear energy relies on tritium, it is unclear whether it was due to genuine knowledge or the negative associations demonstrated by the next results.

In support of H2, compared to solar energy, participants estimated that nuclear energy relies more on nitrogen trifluoride $(\beta=0.94, t(394)=10.64, p<.001)$, even though solar energy, and not nuclear energy, relies on nitrogen trifluoride.

In support of $\mathrm{H} 3$, compared to wind turbines, participants estimated that nuclear energy relies more on neodymium $(\beta=1.02, \mathrm{t}(394)=11.74, \mathrm{p}<.001)$, even though wind turbines, and not nuclear energy, relies on neodymium.

In support of $\mathrm{H} 4$, participants estimated that nuclear energy relies on the harmful made-up substance drisonium more than renewables $(ß=0.93, \mathrm{t}(790)=12.41, \mathrm{p}<.001)$, and natural gas $(\beta=0.50, t(394)=5.18, p<.001)$, even though none of these energy sources rely on it.

In support of $\mathrm{H} 5 \mathrm{a}$, participants considered that nuclear energy emitted more $\mathrm{CO} 2$ than renewable energies $(\beta=0.89, \mathrm{t}(691)=-11.62, \mathrm{p}<.001)$, which is inaccurate (they all emit very small amounts of $\mathrm{CO} 2$ ).

Contrary to $\mathrm{H} 5 \mathrm{~b}$, participants considered that nuclear energy emitted less $\mathrm{CO} 2$ than natural gas plants $(ß=-0.52, \mathrm{t}(394)=-5.37, \mathrm{p}<.001)$, which is accurate. 
In support of H6a and H6b, participants considered that nuclear energy caused greater harm to the environment than renewables $(\beta=1.51, \mathrm{t}(790)=24.43, \mathrm{p}<.001)$, and natural gas plants $(\beta$ $=0.53, \mathrm{t}(394)=5.43, \mathrm{p}<.001)$.

In support of $\mathrm{H} 7, \mathrm{CO} 2$ emissions estimations correlated with the perceived negative ecological impact of nuclear energy $(\mathrm{r}=0.46[0.34,0.56], \mathrm{p}<.001)$.

The results from $\mathrm{H} 2$ to $\mathrm{H} 4$ are presented in Figure 2.
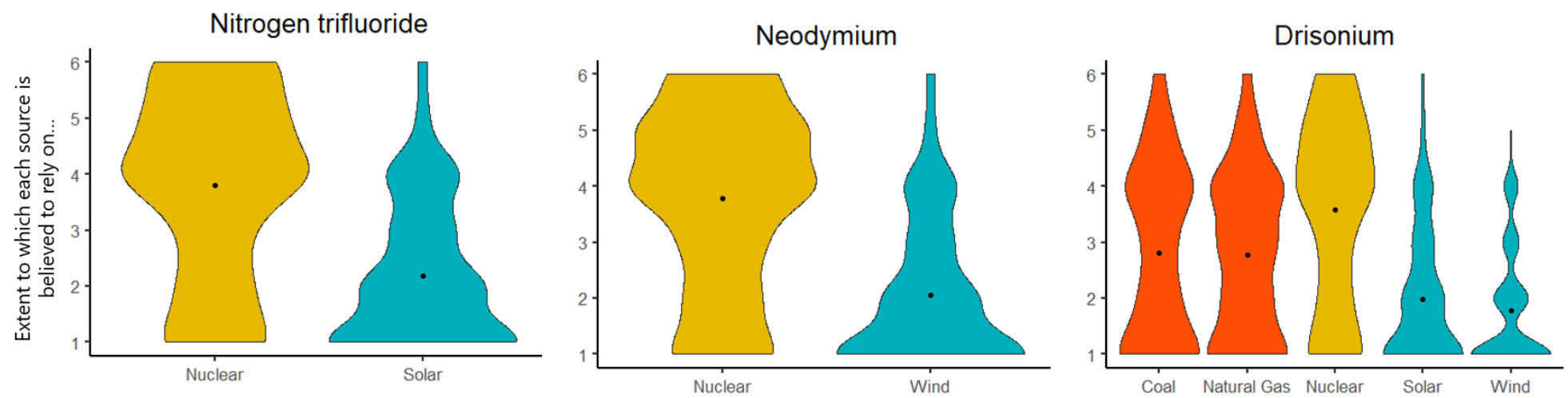

Figure 2. Distributions and means representing the extent to which the energy sources were believed to rely on three substances described as harmful. Participants believed nuclear power was particularly likely to rely on all three substances, although it is wind turbines that rely on neodymium, solar panels that rely on nitrogen trifluoride, and drisonium is made-up. Responses range from 1 to 6 , " 1 " means that the energy source does not rely at all on the substance and " 6 " that it relies a great deal on it.

\section{Exploratory analysis}

Finally, we investigated whether prior beliefs about nuclear energy are correlated with the acquisition of the belief that it relies on drisonium, a made-up substance described as harmful. We found that the estimated impact of nuclear energy on climate change and its estimated level of $\mathrm{CO} 2$ emissions are both correlated with the belief that it emits drisonium $(\mathrm{r}=.26[.13, .39]$ and $\mathrm{r}=.47[.36, .57])$. 


\section{Discussion}

The results confirm the broadly negative perception of nuclear energy observed in the UK, with $54 \%$ of participants answering that it emitted some, a lot, or a great deal of CO2, and believing nuclear power to be more damaging to the environment than natural gas, a fossil fuel. More importantly, participants believed that nuclear energy relies more than other energy sourcesincluding renewables but also coal and natural gas-on a made-up harmful substance. Participants also believed that nuclear energy relies on harmful substances such as neodymium and nitrogen trifluoride more than the energy sources actually relying on them. This suggests that specific negative misconceptions about nuclear energy are likely a byproduct of negative beliefs about nuclear energy (e.g. the belief that it emits pollutants).

\section{Experiment 2}

Experiment 2 replicates in a different population (French participants) the results of Experiment 1, while improving on its design. First, we expect to observe the same association between nuclear power and various substances:

- H1: Participants estimate that nuclear energy relies on nitrogen trifluoride more than solar energy.

- H2: Participants estimate that nuclear energy relies on neodymium more than wind turbines.

- H3: Participants estimate that nuclear energy relies on calisnon more than renewables and natural gas.

The name of the made-up substance has been changed from drisonium to calisnon, so that the name might not be phonetically associated with nuclear energy. In the previous experiment, all the products were described as harmful. The results of the experiment could thus be explained 
by a general tendency to associate any substance, regardless of its harmfulness, to nuclear energy. To test whether participants' bias is specific to harmful substances we introduced a new made-up substance, described as harmless. We then compared whether participants were more likely to associate energy sources with the harmful or the harmless made-up substances.

- H4: Compared to renewable, participants will associate nuclear energy with the harmful made-up substance more than with the harmless made-up substance.

We also tested the hypotheses regarding the negative image of nuclear energy and its production of $\mathrm{CO} 2$ :

- H5: Participants consider that nuclear power plants emit more $\mathrm{CO} 2$ than renewable energies (a), and natural gas (b), considered separately.

- H6: Participants consider that nuclear power plants are more harmful for the environment than renewable energies (a), and natural gas (b), considered separately.

- H7: Considering nuclear energy as harmful to the environment correlates with the belief that it emits $\mathrm{CO} 2$.

Finally, to test whether the perception that nuclear plants emit large amounts of harmful substances is driven by the image of their chimneys emitting large clouds of smoke, we asked participants whether they believed that certain pollutants could be found in that smoke:

- H8: Participants wrongly associate pollutants with smoke emitted from nuclear power plant stacks.

\section{Participants}


Based on a pre-registered power analysis, we recruited 209 French participants on Crowdpanel. We removed four participants who failed the attention check, and one who didn't report his age, leaving 204 participants ( 110 women, $\left.M_{\text {Age }}=41.85, S D=13.67\right)$.

\section{Materials, Design and Procedure}

Materials, design, and procedure are identical to the first experiment, except that we introduced two made-up substances instead of one (tranain, described as harmless, and calisnon, described as harmful), and added a question concerning the content of nuclear power plants' chimney's emissions. The French translations were done and checked by native speakers.

We measured the belief that nuclear energy emitted pollutants through their chimneys with the question: "According to you, what is the smoke going out of the nuclear power plants chimneys made of? You can select several options" ([Toxic gas], [Water vapor], [CO2], [Radioactive gas]). Note that the correct answer here is water vapor.

\section{Results}

We conducted ordinary least squares (OLS) regressions and controlled for multiple comparisons applying the Benjamini-Hochberg method to H1-8. The results from H1-4 are presented in Figure 3. First, we found that participants believed nuclear energy relies on

nitrogen trifluoride more than solar energy (panel a), and that nuclear energy relies on neodymium more than wind turbines (panel b). Second, we see in panel c that nuclear energy (in yellow) and coal (in red) were rated as relying on the harmful made-up substance more than on the harmless made-up substance. Whereas renewables (in blue) were rated as relying on the harmless made-up substance more than on the harmful made-up substance. 

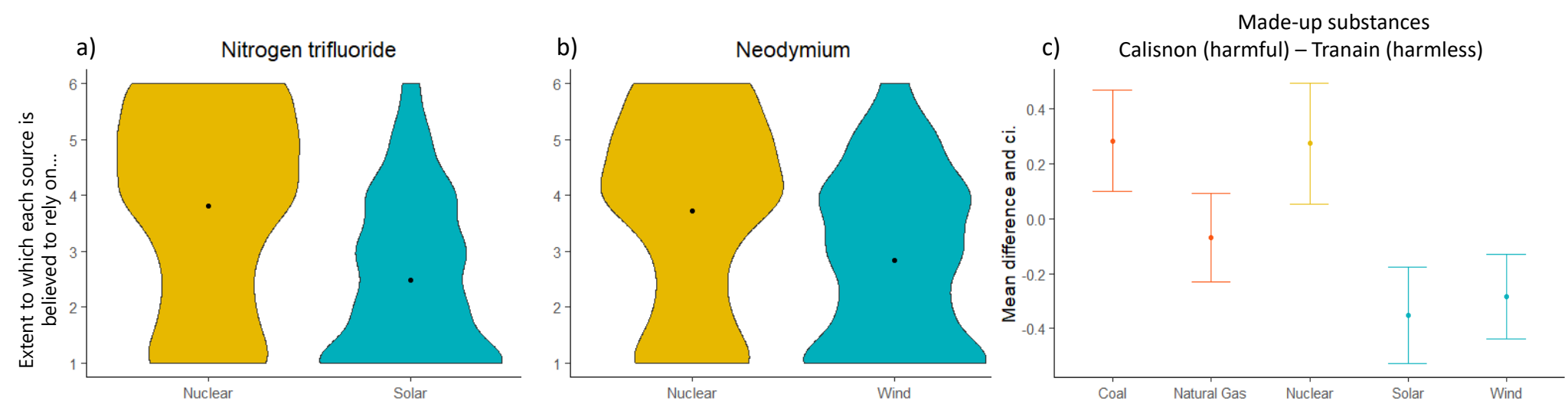

Figure 3. Distributions and means of the rated associations between energy sources and various substances described as harmful. In panel a and b, responses range from 1 to 6 , "1" means that the energy source does not rely at all on the substance while " 6 " that it relies a great deal on it. In panel c, the mean difference between calisnon and tranain captures the extent to which participants estimated that the energy sources relied on the harmful made-up substance more than on the harmless made-up substance.

In support of $\mathrm{H} 1$, participants estimated that nuclear energy relies on nitrogen trifluoride more than solar energy $(ß=1.32, \mathrm{t}(406)=8.43, \mathrm{p}<.001)$, even though solar energy, and not nuclear energy, relies on nitrogen trifluoride.

In support of $\mathrm{H} 2$, participants estimated that nuclear energy relies on neodymium more than wind turbines $(\beta=0.88, \mathrm{t}(406)=5.52, \mathrm{p}<.001)$, even though wind turbines, and not nuclear energy, relies on neodymium.

In support of $\mathrm{H} 3$, participants estimated that nuclear energy relies on the harmful made-up substance calisnon more than renewables $(\beta=1.00, \mathrm{t}(814)=8.19, \mathrm{p}<.001)$, and natural gas $(\beta$ $=0.62, \mathrm{t}(406)=3.74, \mathrm{p}<.001)$. 
In support of H4, compared to renewables, participants were more likely to associate nuclear energy with the harmful rather than with the harmless made-up substance $(B=0.39, \mathrm{t}(814)$ $=4.95, \mathrm{p}<.001)$. In particular, participants estimated that nuclear energy relies on calisnon (harmful made-up substance) more than tranain (harmless made-up substance), whereas they estimated that renewables rely on tranain more than calisnon (see Figure 3).

In support of $\mathrm{H} 5 \mathrm{a}$, participants considered that nuclear power plants emitted more $\mathrm{CO} 2$ than renewables $(\beta=1.46, t(814)=13.36, p<.001)$, but contrary to $H 5 b$, that nuclear energy emitted less $\mathrm{CO} 2$ than natural gas plants $(\beta=-0.30, \mathrm{t}(406)=-2.09, \mathrm{p}=0.038)$.

In support of H6a and H6b, participants considered that nuclear plants were more harmful for the environment than renewables $(\beta=2.19, \mathrm{t}(814)=21.90, \mathrm{p}<.001)$, and natural gas plants $(\beta$ $=0.72, \mathrm{t}(406)=5.96, \mathrm{p}<.001)$.

In support of $\mathrm{H} 7$, we found that estimations of $\mathrm{CO} 2$ emissions correlated with the perceived ecological impact of nuclear energy $(r=0.57, t(202)=9.96, p<.001)$.

To test H8, we calculated a nuclear pollution score that quantifies the degree to which each participant thinks nuclear energy emits some pollutant through its chimneys. The correct answer (water vapor) yielded -1 , while each incorrect answer yielded a +1 . The score thus ranged from -1 (participants who correctly only answered water vapor) to 3 (participants who answered all the pollutants, but not water vapor). A t-test enabled us to reject the null hypothesis according to which the mean of the scores was equal to -1 (Mean $=-.10, t(1223)=27.43, p<$ .001 ). Descriptively, $55 \%$ mentioned only water vapor, $20 \%$ mentioned toxic gas, $11 \%$ mentioned radioactive gas, $34 \%$ mentioned $\mathrm{CO} 2$.

\section{Exploratory analysis}


Finally, we investigated whether prior beliefs about nuclear energy are associated with the acquisition of the belief that it relies on harmful, rather harmless, made-up substances. We found that the estimated impact of nuclear energy on climate change and its estimated level of CO2 emissions are (weakly) correlated with the belief that nuclear energy relies on harmful rather than harmless made-up substances $(\mathrm{r}=.16[.02, .29])$. In other words, the more participants believed that nuclear energy contributes to climate change and emits $\mathrm{CO} 2$, the more likely they were to develop the belief that it relies on harmful made-up substances rather than harmless made-up substances.

\section{Discussion}

Experiment 2 replicated and extended the results of Experiment 1 in a different population (France instead of UK). The results show the broadly negative perception of nuclear energy in France, with $56 \%$ of participants answering that it emitted some, a lot, or a great deal of $\mathrm{CO} 2$, and believing nuclear power to be more damaging to the environment than natural gas, a fossil fuel. The results confirm that participants easily develop specific misconceptions about substances that nuclear energy relies on, and that this acquisition is facilitated when the substances are described as harmful rather than harmless. The opposite is true for renewables. We also found that nearly half of the participants believe the smoke emitted by nuclear power plants' chimneys to contain pollutants. Overall, Experiment 2 thus further suggests that the specific harmful effects attributed to nuclear power are a byproduct of negative prior beliefs about nuclear energy.

\section{Experiment 3}

Experiments 1 and 2 show that people think that nuclear energy relies on harmful substances that are in no way related to nuclear energy. This suggests that general negative beliefs about nuclear energy drives these attributions, which could explain why so many people also believe 
that nuclear energy emits significant amounts of $\mathrm{CO} 2$, an especially problematic misconception. In Experiment 3, we test whether reading an argument dispelling this misconception leads participants to believe that nuclear energy contributes less to climate change (H2). To control for task demands, other participants were presented with arguments in favor of nuclear energy, but which were unrelated to its $\mathrm{CO} 2$ emissions: one bore on the harmlessness of radioactivity during normal nuclear plant functioning, and the other on some advantages of nuclear energy in terms of energy supply ${ }^{2}$. We also formulated hypotheses bearing on these two arguments, leading to the following hypotheses:

- H1: Participants who read the argument on the low CO2 emissions of nuclear energy believe that it emits less $\mathrm{CO} 2$ than those who read arguments on the topics of radioactivity and energy supply, controlling for participant's prior opinions.

- H2: Participants who read the argument on the low CO2 emissions of nuclear energy believe that nuclear energy contributes less to climate change than participants who read arguments on the topics of radioactivity and energy supply, controlling for participant's prior opinions.

- H3: Participants who read the argument on the harmlessness of the radioactivity emitted by nuclear energy consider the radiation levels of nuclear energy to be less dangerous than participants who read arguments on the topics of CO2 emissions and energy supply, controlling for participant's prior opinions.

\footnotetext{
${ }^{2}$ Two studies offering support for H1 were conducted prior to Experiment 3 (see ESM). However, these results are open to an alternative interpretation: the $\mathrm{CO} 2$ Emissions Argument was accompanied by another argument, which led to an increased perception that renewables emit $\mathrm{CO} 2$. This increase could in turn explain why participants believed that nuclear energy plays a relatively smaller role in climate change, without any change in the absolute role of nuclear energy.
} 
- H4: Participants who read the argument on the positive contribution of nuclear energy to the stability of energy supply consider nuclear energy benefits regarding energy supply to be higher than participants who read arguments on the topics of $\mathrm{CO} 2$ emissions and radioactivity, controlling for participant's prior opinions.

\section{Participants}

Based on a pre-registered power analysis, we recruited 305 UK participants on Prolific Academic. We removed nine participants who failed the attention check, leaving 296 participants (201 women, $M_{\text {Age }}=37.57, S D=11,82$ ).

\section{Materials and procedure}

After completing a consent form, participants were asked their opinion on nuclear energy. Afterwards, participants were assigned to one of three conditions, and they received one of three arguments in favor of nuclear energy: an argument on the benefits of nuclear energy regarding the stability of the energy supply (Energy Supply Condition); an argument on the limited $\mathrm{CO} 2$ emissions of nuclear energy production (CO2 Emission Condition); and an argument on the limited effect of nuclear radiation (Radiation Condition). Opinions on nuclear energy were measured again.

Opinions on nuclear energy before and after treatment were measured as follows.

Opinion on the amount of $\mathrm{CO} 2$ emitted from nuclear power plants was measured with: "How much $\mathrm{CO} 2$ do you think each of the following energy sources emits?" ([None at all], [A very small amount], [A small amount], [An average amount], [A large amount], [A very large amount]). 
Opinion on the contribution of different energy sources to climate change was measured with: "To what extent do you consider that each of the following energy sources contributes to climate change?" (Coal, Nuclear, Natural Gas, Oil, Solar, Wind) ([None at all], [A very small amount], [A small amount], [An average amount], [A large amount], [A very large amount]).

Opinion on the radioactive dangers of nuclear energy on health was measured with: "Do you think that nuclear power plants emit dangerous levels of radiation that could lead to health problems?” ([Strongly disagree], [Somewhat disagree], [Neither agree nor disagree], [Somewhat agree], [Strongly agree]).

Opinion on the benefits of nuclear energy considering the stability of energy supply was measured with: "Do you think that the use of nuclear power is necessary to guarantee energy supply?" ([Strongly disagree], [Somewhat disagree], [Neither agree nor disagree], [Somewhat agree], [Strongly agree]).

The three following arguments were used:

$\mathrm{CO} 2$ Emission Argument

$\mathrm{CO} 2$ emissions are the main driver of climate change, and most efforts aimed at slowing climate change have focused on reducing our production of CO2. It has been established that nuclear energy produces the same, low amount of $\mathrm{CO} 2$ as renewables (such as solar power or wind power), which is around 70 times less than natural gas power plants, 120 times less than fuel-fired power plants, and 180 times less than coal power plants. Nuclear plants and renewables hence emit a very low amount of $\mathrm{CO} 2$ to produce energy in comparison with other energy sources.

Radiation Argument

Radioactivity is completely unlike a viral or bacterial disease: low doses of radiation 
are perfectly harmless, and radiation is not contagious. Radiation exposure can occur from natural sources, such as radioactivity in rocks and soil, or cosmic radiation. Radiation arising from human activities is not different from natural radiation. Less than $1 \%$ of exposure is due to the generation of electricity in nuclear power plants. You get more exposure to radiation by taking a plane or getting a dental X-ray than by living next to a nuclear power plant.

\section{Energy Supply Argument}

We need to build new nuclear power plants because even if we develop as much as possible wind, solar, biomass and existing hydraulic power, it will not be possible to supply all the electricity we need, especially with the increasing use of new technologies and electric vehicles. When there is no wind or no sun, nuclear power plants are able to take over the production of electricity.

\section{Results}

A linear regression with perceptions post-treatment regressed on perceptions pre-treatment, showed that our manipulation check was validated: after having read the $\mathrm{CO} 2$ Emission Argument participants estimated that nuclear energy emits less CO2 $(b=-1.26, t(178.54)=-$ $6.51, \mathrm{p}<.001)$ - while reading the $\mathrm{CO} 2$ Emission Argument did not lead to a significant increase in the perceived CO2 emissions of renewables $(b=-.18, t(191.01)=1.49, p=.14)$. To test the hypotheses reported below, we regressed perceptions post-treatment on a dummy variable "Condition" with nuclear energy set as baseline, and added perceptions pre-treatment as predictor to control for this factor. Figure 4 and Table 1 offer a descriptive overview of the results.

In favor of $\mathrm{H} 1$, after having read the $\mathrm{CO} 2$ Emission Argument, participants estimated that nuclear energy emits less CO2 compared to participants who read the Energy Supply Argument 
$(ß=-1.07, \mathrm{t}(292)=-7.72, \mathrm{p}<.001)$, and participants who read the Radiation Argument $(\beta=-$ $0.52, \mathrm{t}(292)=-3.71, \mathrm{p}<.001)$, controlling for participants' prior opinions.

In favor of $\mathrm{H} 2$, after having read the $\mathrm{CO} 2$ Emission Argument, participants believed that nuclear energy contributes less to climate change compared to participants who read the Energy Supply Argument $(\beta=-0.83, \mathrm{t}(292)=-5.81, \mathrm{p}<.001)$ and participants who read the Radiation Argument $(\beta=-0.40, \mathrm{t}(292)=-2.83, \mathrm{p}=0.006)$ — controlling for participants' prior opinions.

In favor of H3, after having read the Radiation Argument, participant believed that nuclear energy was less dangerous for health compared to participants who read the $\mathrm{CO} 2$ Emission Argument $(ß=-0.74, \mathrm{t}(292)=-5.88, \mathrm{p}<.001)$ and participants who read the Energy Supply Argument $(ß=-0.88, \mathrm{t}(292)=-7.10, \mathrm{p}<.001)$ — controlling for participants' prior opinions.

In favor of H4, after having read the Energy Supply Argument, participants believed that nuclear energy was a better asset in terms of energy supply compared to participants who read the CO2 Emission Argument $(\beta=0.22, \mathrm{t}(292)=2.25, \mathrm{p}=0.025)$ and participants who read the Radiation Argument $(\beta=0.44, \mathrm{t}(292)=4.59, \mathrm{p}<.001])$-controlling for participants' prior opinions.
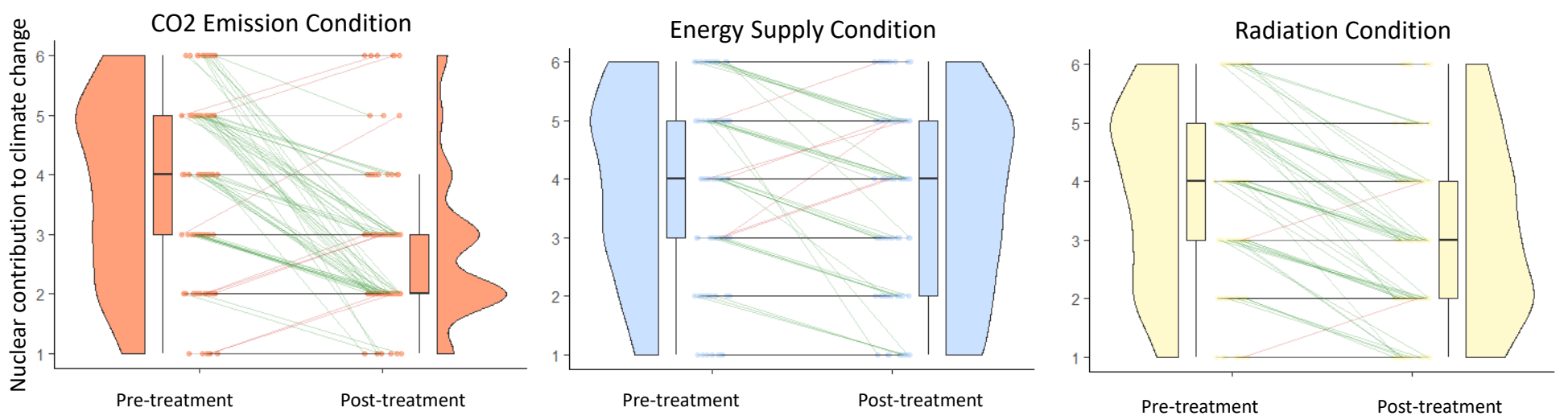
Figure 4. Pre- and post-treatment opinion that nuclear energy contributes to climate change, for the three arguments used in Experiment 3 (participants in the UK). The left and right half violin plots represent the distribution of answers pre- and-post treatment. The red, green, and grey lines respectively indicate participants whose scores have increased, decreased, or not changed after reading the argument. In each condition, scores range from 1 to 6 , and correspond to participants considering nuclear energy to be from "not at all" (1) to "a very large" (6) contributor to climate change.

\begin{tabular}{|c|c|c|c|c|c|c|}
\hline & \multicolumn{2}{|c|}{ CO2 } & \multicolumn{2}{c|}{ Energy supply } & \multicolumn{2}{c|}{ Radiation } \\
\hline & Pre & Post & Pre & Post & Pre & Post \\
\hline $\begin{array}{c}\text { Amount of CO2 emissions of } \\
\text { nuclear energy }\end{array}$ & $3.93(1.53)$ & $2.66(1.15)$ & $3.85(1.57)$ & $3.68(1.55)$ & $3.62(1.68)$ & $2.98(1.45)$ \\
\hline $\begin{array}{c}\text { Neccessity of nuclear power } \\
\text { for energy supply }\end{array}$ & $3.21(1.10)$ & $3.61(1.02)$ & $3.21(.97)$ & $3.83(.92)$ & $3.19(1.08)$ & $3.38(1.07)$ \\
\hline $\begin{array}{c}\text { Nuclear power plants emit } \\
\text { dangerous levels of radiation }\end{array}$ & $3.43(1.12)$ & $3.08(1.16)$ & $3.42(1.03)$ & $3.22(1.12)$ & $3.12(1.16)$ & $2.16(1.04)$ \\
\hline $\begin{array}{c}\text { Nuclear energy contributes to } \\
\text { climate change }\end{array}$ & $3.80(1.53)$ & $2.69(1.24)$ & $3.91(1.55)$ & $3.59(1.58)$ & $3.86(1.53)$ & $3.13(1.51)$ \\
\hline
\end{tabular}

Table 1. Means and Standard Deviations of perceptions pre- and post-treatment, as a function of the type of argument provided.

\section{Discussion}

Participants were presented with one of three arguments in favor of nuclear energy, one of which explaining that it emitted very low amounts of $\mathrm{CO} 2$. Each argument changed participants' beliefs regarding its specific content, and the argument regarding $\mathrm{CO} 2$ emissions also led participants to believe that nuclear energy was less responsible for climate change. 


\section{Experiment 4}

To test the robustness of the results of Experiment 3, it was replicated with French participants (instead of UK participants). The only change was the addition of a question measuring general opinion on nuclear energy, added for exploratory purposes.

\section{Participants}

Based on a pre-registered power analysis, we recruited 309 French participants on Crowdpanel. We removed four participants who failed the attention check, leaving 305 participants (169 women, $\left.M_{\text {Age }}=40.02, S D=13.3\right)$.

\section{Methods}

Procedures and materials are identical to those of Experiment 3, with the addition of the following question: "Do you think that nuclear energy is a good energy source?" ([Strongly disagree], [Somewhat disagree], [Neither agree nor disagree], [Somewhat agree], [Strongly agree]). The French translations were written and checked by native speakers.

\section{Results}

A linear regression with perceptions post- regressed on perceptions pre-treatment, showed that our manipulation was validated: after having read the argument on $\mathrm{CO} 2$ emissions participants estimated that nuclear energy emits less CO2 $(b=-0.79, \mathrm{t}(182.83)=-3.61, \mathrm{p}<.001)$-while reading the $\mathrm{CO} 2$ Emission Argument did not lead to a significant increase in the perceived $\mathrm{CO} 2$ emissions of renewables $(b=-.15, t(196.93)=1.11, p=.27)$.

To test the hypotheses reported below, we regressed perceptions post-treatment on a dummy variable "Condition" with nuclear energy set as baseline, and added perceptions pre-treatment as predictor to control for it. Figure 5 and Table 2 offer a descriptive overview of the results. 
In favor of $\mathrm{H} 1$, after having read the $\mathrm{CO} 2$ Emission Argument, participants estimated that nuclear energy emits less CO2 compared to participants who read the Energy Supply Argument $(ß=-0.79, \mathrm{t}(301)=-5.50, \mathrm{p}<.001])$ and participants who read the Radiation Argument $(\beta=-$ $0.69, \mathrm{t}(301)=-4.82, \mathrm{p}<.001)$, controlling for participants' prior opinions.

In favor of $\mathrm{H} 2$, after having read the $\mathrm{CO} 2$ Emission Argument, participants believed that nuclear energy contributes less to climate change compared to participants who read the Energy Supply Argument $(\beta=-0.72, \mathrm{t}(292)=-4.77, \mathrm{p}<.001)$ and participants who read the Radiation Argument $(\beta=-0.44, t(301)=-2.92, p=0.010])$, controlling for participants' prior opinions.

In favor of H3, after having read the Radiation Argument, participants believed that nuclear energy was less dangerous for health compared to participants who read the $\mathrm{CO} 2$ Emission Argument $(ß=-0.49, \mathrm{t}(301)=-4.74, \mathrm{p}<.001)$ and participants who read the Energy Supply Argument $(ß=-0.69, \mathrm{t}(301)=-6.68, \mathrm{p}<.001])$, controlling for participants' prior opinions.

Regarding H4, after having read the Energy Supply Argument, participants were not significantly more likely to believe that nuclear energy was a better asset in terms of energy supply compared to participants who read the CO2 Emission Argument $(ß=0.14, \mathrm{t}(301)=$ $1.57, \mathrm{p}=0.127)$, controlling for participants' prior opinions. However, after having read the Energy Supply Argument, participants believed that nuclear energy was a better asset in terms of energy supply compared to participants who read the Radiation Argument $(\beta=0.31, \mathrm{t}(301)$ $=3.42, \mathrm{p}<.001)$, controlling for participants' prior opinions.

Regarding general opinion on nuclear energy, reading the $\mathrm{CO} 2$ Emission $\operatorname{Argument}(\beta=0.28$, $t(196.85)=1.98, p=0.060)$, or the Energy Supply Argument $(ß=0.23, t(201.96)=1.39, p=$ 0.166) had no significant effect on general opinion on nuclear energy, whereas reading the Radiation Argument improved participants general opinion on nuclear energy $(B=0.36$, 
$\mathrm{t}(202.59)=2.16, \mathrm{p}=0.032)$. Note that here we use a binary cutoff $($ alpha $=5 \%$ after correction $)$ but that the effect of these three conditions are not statistically distinguishable from each other.
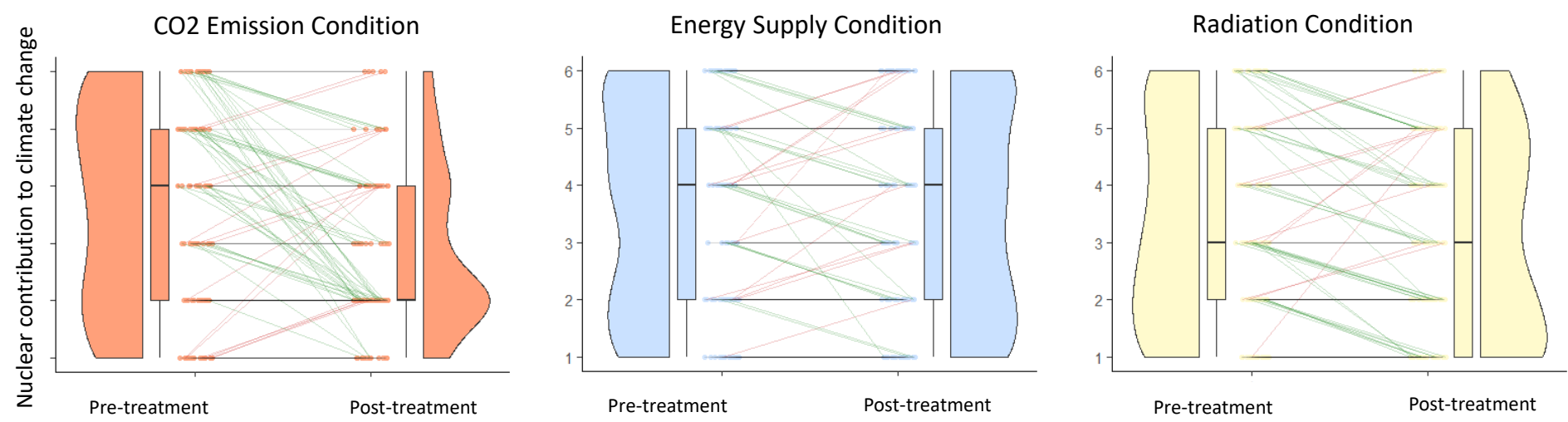

Figure 5. Pre- and post-treatment opinion that nuclear energy contributes to climate change, for the three arguments used in Experiment 3 (participants in France). The left and right half violin plots represent the distribution of answers pre- and-post treatment. The red, green, and grey lines respectively indicate participants whose scores have increased, decreased, or not changed after reading the argument. In each condition, scores range from 1 to 6 , and correspond to participants considering nuclear energy to be from "not at all" (1) to "a very large" (6) contributor to climate change.

\begin{tabular}{|c|c|c|c|c|c|c|}
\hline & \multicolumn{2}{|c|}{ CO2 } & \multicolumn{2}{c|}{ Energy supply } & \multicolumn{2}{c|}{ Radiation } \\
\hline $\begin{array}{c}\text { Amounts of CO2 emissions } \\
\text { of nuclear energy }\end{array}$ & $3.45(1.75)$ & $2.66(1.30)$ & $3.57(1.75)$ & $3.54(1.77)$ & $3.52(1.80)$ & $3.41(1.75)$ \\
\hline $\begin{array}{c}\text { Neccessity of nuclear power } \\
\text { for energy supply }\end{array}$ & $3.50(1.03)$ & $3.67(1.01)$ & $3.54(1.07)$ & $3.84(.95)$ & $3.65(1.08)$ & $3.62(1.16)$ \\
\hline $\begin{array}{c}\text { Nuclear power plants emit } \\
\text { dangerous levels of radiation }\end{array}$ & $3.14(1.72)$ & $2.92(1.11)$ & $3.21(1.29)$ & $3.17(1.29)$ & $3.21(1.29)$ & $2.49(1.19)$ \\
\hline
\end{tabular}




\begin{tabular}{|c|c|c|c|c|c|c|}
\hline $\begin{array}{c}\text { Nuclear energy contributes to } \\
\text { climate change }\end{array}$ & $3.60(1.73)$ & $2.79(1.39)$ & $3.63(1.80)$ & $3.53(1.82)$ & $3.39(1.76)$ & $3.08(1.73)$ \\
\hline
\end{tabular}

Table 2. Means and Standard Deviations of perceptions pre- and post-treatment, as a function of the type of argument provided.

\section{Discussion}

Experiment 4 replicated the main results of Experiment 3, with the exception that the argument bearing on energy supply proved less effective. Moreover, the radiation argument improved the general opinion on nuclear energy. These results confirm that informing participants that nuclear energy emits low amounts of $\mathrm{CO} 2$ is effective in reducing their belief that nuclear energy contributes to climate change.

\section{Conclusion}

In most countries, people's opinion on nuclear energy diverges from that of experts both on specific points (e.g. how much $\mathrm{CO} 2$ nuclear energy emits), and in broader attitudes (in particular, the role of nuclear energy in causing or addressing climate change). In two experiments (in the UK and France), we show that participants quickly form novel misconceptions about nuclear energy: nuclear energy is particularly likely to be associated with harmful substances actually generated by renewable energy, or even with made-up substances. Since such misconceptions could not have been acquired previously by the participants, their emergence during the experiment shows that the misconceptions are driven by negative beliefs about nuclear energy. Moreover, both experiments confirm that participants hold overly negative beliefs about nuclear energy, in particular regarding its emissions of CO2 (mistakenly judged to be significantly higher than those of renewables), and its impact on the environment (judged to be higher than that of natural gas, a fossil fuel). These results are compatible with 
an interpretation in terms of motivated reasoning, by which participants would attribute negative traits to nuclear energy to justify their rejection of this type of energy production (Haidt, 2001; Kunda, 1990; Mercier \& Sperber, 2011). However, the results could also be interpreted as reflecting a rational mechanism of Bayesian updating, by which participants' negative prior beliefs about nuclear energy would be used to interpret novel evidence (see, Tappin et al. 2020).

Why would people hold overly negative beliefs about nuclear energy? A common answer is that these negative beliefs are caused by the media (e.g. Gamson \& Modigliani, 1989; Koerner, 2014; Palfreman, 2006), whose coverage of nuclear energy tends to be negative (see, e.g., Friedman et al., 1987; Stowers, 2017; Koerner, 2014). It has also been suggested that these negative beliefs could be driven by deeper cognitive factors: nuclear energy might trigger a 'behavioral immune system,' (see, e.g. Tybur \& Lieberman, 2016), leading to an overly strong fear of radiation and, in turn, of nuclear energy more generally (Hacquin et al. 2022; Rozin, 2001).

Whatever the cause of these negative beliefs about nuclear energy might be, they are persistent, prevalent across many countries, and, according to the present experiments, they appear to cause specific misconceptions about nuclear energy. As a result, it might seem futile to attempt to tackle these specific misconceptions, such as the widespread idea that nuclear energy releases significant amounts of $\mathrm{CO} 2$. However, in Experiments 3 and 4, we show that informing participants (in the UK and France) about the low levels of $\mathrm{CO} 2$ emitted by nuclear energy leads them not only to change their minds on this specific point, but also more generally on the role played by nuclear energy in climate change. As a result, targeted information campaigns might be able to correct specific misconceptions about nuclear energy, and to bring public opinion closer to expert opinion on the topic of nuclear energy. 
Our research has several limitations. Although arguably the most problematic misconception about nuclear energy is that it emits significant amounts of $\mathrm{CO} 2$, Experiments 1 and 2 did not directly test whether this misconception is caused by generally negative attitudes towards nuclear energy, an issue that future studies might attempt to test. The length of the arguments across the conditions of Experiments 3 and 4 was not equated, such that the greater persuasiveness of the $\mathrm{CO} 2$ argument could be partly attributed to its greater length. However, differences in length cannot account for the differences in the domains in which the $\mathrm{CO} 2$ argument proved more persuasive (i.e. $\mathrm{CO} 2$ production and climate change), or for the fact that no differences in persuasiveness were observed across arguments of different length (e.g. CO2 and radiation arguments). Another limitation is that our results have been gathered in two western countries, with broadly similar perceptions of nuclear power. Although these results are of practical import, since both France and the UK rely on nuclear power, from a theoretical point of view, it would be interesting to replicate our results in countries with more positive or more negative attitudes towards nuclear energy. In other words, we do not assume that our results would replicate in different national contexts.

Besides overcoming these two limitations, future studies could also address, for instance, the importance of the source of the arguments provided to participants: would a source perceived as being pro-nuclear energy lower the persuasiveness of the pro-nuclear energy arguments, and vice versa? Despite their limitations, our experiments help better understand the origin of misconceptions about nuclear energy, and how they can be remedied.

\section{Acknowledgements}

The internship of the first author was funded by EDF (Electricité de France). HM's work is funded by an ANR grant (SCALUP ANR-21-CE28-0016-01). 


\section{References}

ADEME (2022). Base carbone v19.0. https://data.ademe.fr/datasets/base-carbone(r)

Allen, M., Dube, O. P., Solecki, W., Aragón-Durand, F., Cramer, W., Humphreys, S., ... \& Mulugetta, Y. (2018). Global warming of $1.5^{\circ}$ C. An IPCC Special Report on the impacts of global warming of $1.5^{\circ} \mathrm{C}$ above pre-industrial levels and related global greenhouse gas emission pathways, in the context of strengthening the global response to the threat of climate change, sustainable development, and efforts to eradicate poverty. Sustainable Development, and Efforts to Eradicate Poverty.

Atir, S., Rosenzweig, E., \& Dunning, D. (2015). When Knowledge Knows No Bounds. Psychological Science, 26(8), 1295-1303. https://doi.org/10.1177/0956797615588195

Barrera, O., Guriev, S., Henry, E., \& Zhuravskaya, E. (2020). Facts, alternative facts, and fact checking in times of post-truth politics. Journal of Public Economics, 182, 104123.

Boice, J. D., Bigbee, W. L., Mumma, M. T., \& Blot, W. J. (2003). Cancer incidence in municipalities near two former nuclear materials processing facilities in Pennsylvania. Health Physics, 85(6), 678-690. https://doi.org/10.1097/00004032-200312000-00013

Budnitz, R. J. (2016). Nuclear power: Status report and future prospects. Energy Policy, 96, 735- 739. https://doi.org/10.1016/j.enpol.2016.03.011

BVA Orano. (2019). Les Français et le nucléaire. https://www.bvagroup.com/sondages/francais-nucleaire-sondage-bva-orano/

Cameron, R., \& Taylor, M. (2011). The 2050 roadmap for nuclear: Making a global difference. Energy and Environment, 22(1-2), 1-15. https://doi.org/10.1260/0958$305 X .22 .1-2.1$ 
Cook, J., \& Jacobs, P. (2014). Scientists are from Mars, laypeople are from Venus: An evidence-based rationale for communicating the consensus on climate. Reports of the National Center for Science Education, 34(6).

Ecker, U. K. H., \& Ang, L. C. (2018). Political Attitudes and the Processing of Misinformation Corrections. Political Psychology, 40(2), 241-260. https://doi.org/10.1111/pops.12494

Eurobarometer. (2014). Energy Technologies: Knowledge, Perception, Measures. Wind Power Technologies and Repowering Considerations as Projects Age, January, 1-74. https://doi.org/10.5772/7355

Flynn, D., Nyhan, B., \& Reifler, J. (2017). The nature and origins of misperceptions: Understanding false and unsupported beliefs about politics. Political Psychology, 38, $127-150$.

Friedman, S. M., Gorney, C. M., \& Egolf, B. P. (1987). Reporting on Radiation: A Content Analysis of Chernobyl Coverage. Journal of Communication, 37(3), 58-67. https://doi.org/10.1111/j.1460-2466.1987.tb00994.x

Haidt, J. (2001). The emotional dog and its rational tail: A social intuitionist approach to moral judgment. Psychological Review, 108(4), 814-834.

Gamson, W. A., \& Modigliani, A. (1989). Media Discourse and Public Opinion on Nuclear Power: A Constructionist Approach. American Journal of Sociology, 95(1), 1-37. https://doi.org/10.1086/229213

GlobeScan. (2005). Global Public Opinion on Nuclear Issues and the IAEA: Final Report from 18 Countries. Global Public Opinion on Nuclear Issues and the IAEA, October, 32.https://web.archive.org/web/20080409124139/http://www.iaea.org/Publications/Re 
ports/gponi_report2005.pdf\%0Ahttp://large.stanford.edu/courses/2015/ph241/1lanos1/ docs/globesca n.pdf

Guess, A., \& Coppock, A. (2018). Does Counter-Attitudinal Information Cause Backlash ? Results from Three Large Survey Experiments. British Journal of Political Science, 50(4), 1497-1515. https://doi.org/10.1017/s0007123418000327

Hacquin, AS., Altay, S., Aarøe, L. \& Mercier, H. (2022) Fear of contamination and public opinion on nuclear energy. Journal of Environmental Psychology. https://doi.org/10.1016/j.jenvp.2021.101749

Ho, S. S., Leong, A. D., Looi, J., Chen, L., Pang, N., \& Tandoc, E. (2018). Science Literacy or Value Predisposition? A Meta-Analysis of Factors Predicting Public Perceptions of Benefits, Risks, and Acceptance of Nuclear Energy. Environmental Communication, 13(4), 457-471. https://doi.org/10.1080/17524032.2017.1394891

IPSOS. (2020). Observatoire COP 2020, Mobilisation, inquiétude ou indifférence des citoyens de 30 pays envers le changement climatique. https://www.edf.fr/sites/default/files/contrib/groupe-edf/obsclimat/2020/obscop2020_principauxresultats 1a fr.pdf

Kahan, D. M., \& Corbin, J. (2016). A Note on the Perverse Effects of Actively Open-Minded Thinking on Climate-change Polarization. SSRN Electronic Journal. Published. https://doi.org/10.2139/ssrn.2819820

Kharecha, P. A., \& Hansen, J. E. (2013). Prevented mortality and greenhouse gas emissions from historical and projected nuclear power. Environmental Science and Technology, 47(12), 6715-6717. https://doi.org/10.1021/es401667h 
Koerner, C. L. (2014). Media, fear, and nuclear energy: A case study. Social Science Journal, 51(2), 240-249. https://doi.org/10.1016/j.soscij.2013.07.011

Kunda, Z. (1990). The case for motivated reasoning. Psychological Bulletin, 108, 480-498.

Masurel, A. H., Altay, S., \& Mercier, H. (2022). Nuclear Energy and CO2 Emissions. osf.io/4ujbw

Mercier, H., \& Sperber, D. (2011). Why do humans reason? Arguments for an argumentative theory. Behavioral and Brain Sciences, 34(2), 57-74.

Myhrvold, N. P., \& Caldeira, K. (2012). Greenhouse gases, climate change and the transition from coal to low-carbon electricity. Environmental Research Letters, 7(1). https://doi.org/10.1088/1748-9326/7/1/014019

NREL (2022). U.S. Life Cycle Inventory Database.https://www.nrel.gov/lci/assessments.html

Nuclear Energy Institute. (2019). A Clear Consensus: Nuclear Energy Must Be Part Of Any Climate Solution.

Nam, H., Konishi, S., \& Nam, K.-W. (2021). Comparative analysis of decision making regarding nuclear policy after the Fukushima Dai-ichi Nuclear Power Plant Accident: Case study in Germany and Japan. Technology in Society, 67, 101735.

Nyhan, B., \& Reifler, J. (2010). When Corrections Fail : The Persistence of Political Misperceptions. Political Behavior, 32(2), 303-330. https://doi.org/10.1007/s11109$010-9112-2$

OECD (2012). The Role of Nuclear Energy in a Low-carbon Energy Future. https://doi.org/10.1787/9789264991897-en 
Oliver, J. E., \& Wood, T. J. (2014). Conspiracy theories and the paranoid style (s) of mass opinion. American Journal of Political Science, 58(4), 952-966.

Palfreman, J. (2006). A tale of two fears: Exploring media depictions of nuclear power and global warming. Review of Policy Research, 23(1), 23-43. https://doi.org/10.1111/j.1541- 1338.2006.00184.x

Paulhus, D. L., Harms, P. D., Bruce, M. N., \& Lysy, D. C. (2003). The over-claiming technique: Measuring self-enhancement independent of ability. Journal of personality and social psychology, 84(4), 890.

Pekel, F. O. (2005). High School Students' and Science Teachers' Philosophical Views on Science. Journal of the Korean Chemical Society, 49(5), 503-512. https://doi.org/10.5012/jkcs.2005.49.5.503

Porter, E., Wood, T. J., \& Velez, Y. (2022). Correcting COVID-19 Vaccine Misinformation in Ten Countries.

Rozin, P. (2001). Technological stigma. In Risk, media and stigma: understanding public challenges to modern science and technology.

Sermage-Faure, C., Laurier, D., Goujon-Bellec, S., Chartier, M., Guyot-Goubin, A., Rudant, J., Hémon, D., \& Clavel, J. (2012). Childhood leukemia around French nuclear power plants The Geocap study, 2002-2007. International Journal of Cancer, 131(5), 20022007. https://doi.org/10.1002/ijc.27425

Stowers, K. (2017). Media Coverage of Nuclear Power. 2017-2019. http://large.stanford.edu/courses/2017/ph241/stowers2/ 
Tappin, B. M., Pennycook, G., \& Rand, D. G. (2020). Bayesian or biased? Analytic thinking and political belief updating. Cognition, 204, 104375. https://doi.org/10.1016/j.cognition.2020.104375

Tybur, J. M., \& Lieberman, D. (2016). Human pathogen avoidance adaptations. Current Opinion in Psychology, 7, 6-11. https://doi.org/10.1016/j.copsyc.2015.06.005

UNSCEAR. (2017). Sources, Effects and Risks of Ionizing Radiation Annex B Epidemiological Studies of Cancer Risk Due To Low-Dose-Rate Radiation From Environmental Sources Contents. http://www.unscear.org/docs/publications/2017/UNSCEAR_2017_Annex-B.pdf

Vainio, A., Paloniemi, R., \& Varho, V. (2016). Weighing the Risks of Nuclear Energy and Climate Change : Trust in Different Information Sources, Perceived Risks, and Willingness to Pay for Alternatives to Nuclear Power. Risk Analysis, 37(3), 557-569. https://doi.org/10.1111/risa.12640

Van der Linden, S. L., Leiserowitz, A. A., Feinberg, G. D., \& Maibach, E. W. (2015). The Scientific Consensus on Climate Change as a Gateway Belief : Experimental Evidence. PLOS ONE, 10(2), e0118489. https://doi.org/10.1371/journal.pone.0118489

Walter, N., Brooks, J. J., Saucier, C. J., \& Suresh, S. (2021). Evaluating the impact of attempts to correct health misinformation on social media: A meta-analysis. Health Communication, 36(13), 1776-1784.

Williams, D. (2022). The marketplace of rationalizations. Economics \& Philosophy, 1-25.

Wood, T., \& Porter, E. (2019). The Elusive Backfire Effect : Mass Attitudes' Steadfast Factual Adherence. Political Behavior, 41(1), 135-163. https://doi.org/10.1007/s11109-0189443-y 
